Available online on 15.05 .2015 at http://jddtonline.info
Journal of Drug Delivery and Therapeutics
Open access to Pharmaceutical and Medical research
(c) 2015, publisher and licensee JDDT, This is an Open Access article which permits unrestricted noncommercial use, provided the original
work is properly cited

RESEARCHARTICLE

\title{
IN VITRO EVALUATION OF CHEMICALLY DEACETYLATED XANTHAN GUM AS MATRIX POLYMER FOR CONTROLLED RELEASE TABLETS
}

\author{
Mahesh Kumar Vishwanadha*, B Shravan Kumar, Rajasri Ch, Mounika G, Ramya D, Saikrupa B ,
}

Department of Pharmaceutical Sciences, Vaageswari Institute of Pharmaceutical Sciences, Beside LMD Police Station, Ramakrishna Colony, Karimnagar, Telangana-505001, India

*Corresponding Author's Email: mahesh55595@gmail.com

Received 18 March 2015; Review Completed 21 April 2015; Accepted 03 May 2015, Available online 15 May 2015

\begin{abstract}
The objective of the present investigation is to prepare Deacetylated Xanthan Gum, a new Xanthan Gum based polymer and to evaluate its application in controlled release (CR) and in the design of Simvastatin controlled release tablets. Deacetylated Xanthan Gum polymer was prepared by gelatinization of Xanthan Gum in the presence of sodium hydroxide. Matrix tablets each containing $40 \mathrm{mg}$ of Simvastatin were formulated employing Deacetylated Xanthan Gum polymer in different proportions of drug and polymer and the tablets were evaluated. Simvastatin release from the formulated tablets was slow and spread over $12 \mathrm{hr}$ and depended on percent polymer in the tablet. Release was diffusion controlled and followed zero order kinetics. Non Fickian diffusion was the drug release mechanism from the formulated tablets. Simvastatin release from matrix tablets F1 formulated employing $37 \%$ Deacetylated Xanthan Gum was found suitable for the design of oral controlled release tablets.
\end{abstract}

Key-words: Deacetylated Xanthan Gum, Controlled release, Simvastatin, Matrix tablets.

\section{INTRODUCTION}

In the recent decades, controlled release dosage forms have made significant progress in terms of formulation technology and therapeutic efficacy. Drug release from the formulation should be at a Predictable rate for better patient compliance. Polymers, which are used as release retarding materials in the design of controlled release dosage forms, play an important role in controlling the release of drug from these dosage forms. Though a wide range of polymers and other release retarding polymeric materials are available, there is a need to develop new materials as the newly discovered API's as well as current Drugs are posing a great deal of challenge in formulating safe and effective formulations. Xanthan Gum is a natural, biodegradable polymer and modified Xanthan Gum is reported as fillers ${ }^{1}$, Disintegrants and dry binders. In the present study, a new Xanthan Gum based polymer, Deacetylated Xanthan Gum was synthesized and evaluated for its application in controlled release ${ }^{2,3}$. Among the various approaches, preparation of matrix tablet is one of the Easiest approaches for obtaining a controlled release. Simvastatin containing matrix tablets were prepared employing Deacetylated Xanthan Gum and evaluated for controlled release. Controlled release formulation is needed for simvastatin because of it is a BCS Class II Drug with low dissolution and high permeability ${ }^{4}$.

\section{MATERIALS AND METHODS}

\section{Materials}

Simvastatin is a gift sample from M/s. Dr. Reddy's Labs Pvt. Ltd., Hyderabad. All other materials used were of Pharmacopoeial grade.

\section{Methods \\ Preparation of deacetylated xanthan gum}

The reactions for deacetylation of xanthan Gum was carried out with $1 \%$ xanthan solutions and sodium hydroxide, in the concentrations 0.01 mol. $\mathrm{L}^{-1}$. An Erlenmeyer flask $(240 \mathrm{ml})$ containing $125 \mathrm{ml}$ of the above solution is incubated in an orbital shaker at 300 RPM. The reaction was pre-set a time of 3 hours and a temperature of $25{ }^{\circ} \mathrm{C}$. The solutions were neutralized with hydrochloric acid $\left(2 \mathrm{~mol} . \mathrm{l}^{-1}\right)$. The biopolymer was recovered by precipitation with ethanol, dried in an oven at $56^{\circ} \mathrm{C}$, until reaching a constant weight and then milled with a disc mill to a particle size of $0.5 \mathrm{~mm}$.

\section{Preparation of tablets}

Matrix tablets each containing $40 \mathrm{mg}$ of Simvastatin were prepared employing Deacetylated Xanthan Gum in different proportions of drug and polymer. The required quantities of Simvastatin and matrix materials were mixed thoroughly in a mortar by following geometric dilution technique. The binder solution (5\% starch) was added and mixed thoroughly to form wet mass. The mass was passed through mesh No. 12 to obtain wet granules. The wet granules were dried at $56^{\circ}$ for $4 \mathrm{~h}$. The dried granules were passed through mesh No. 16 to break the aggregates. The lubricants talc $(5 \mathrm{mg})$ and magnesium stearate $(5 \mathrm{mg})$ were passed 
through mesh No. 100 onto dry granules and blended in a closed polyethylene bag. The tablet granules were compressed into tablets on a rotary multi-station tablet punching machine (Simach Machinery Co. Pvt. Ltd.,
Mumbai) with a hardness of 6 - 8kg/sq.cm. Using $9 \mathrm{~mm}$ round and Concave punches. Hardness of tablets was tested using a Monsanto hardness tester. Friability of tablets was determined in a Roche Friabilator.

Table 1: Composition of Deacetylated Xanthan Gum based controlled release tablets of Simvastatin

\begin{tabular}{|l|l|l|l|l|l|l|l|l|l|}
\hline Formulation code & F1 & F2 & F3 & F4 & F5 & F6 & F7 & F8 & F9 \\
\hline Simvastatin & 40 & 40 & 40 & 40 & 40 & 40 & 40 & 40 & 40 \\
\hline Deacetylated Xanthan gum & 130 & 120 & 110 & 100 & 80 & 60 & 40 & 20 & 00 \\
\hline Lactose & 70 & 75 & 75 & 80 & 85 & 90 & 95 & 100 & 105 \\
\hline Starch & 20 & 25 & 25 & 30 & 35 & 40 & 45 & 40 & 55 \\
\hline MCC & 40 & 40 & 45 & 45 & 40 & 55 & 60 & 65 & 70 \\
\hline PVP-K30 & 40 & 40 & 45 & 45 & 40 & 55 & 60 & 65 & 70 \\
\hline Magnesium stearate & 5 & 5 & 5 & 5 & 5 & 5 & 5 & 5 & 5 \\
\hline Talc & 5 & 5 & 5 & 5 & 5 & 5 & 5 & 5 & 5 \\
\hline
\end{tabular}

\section{In vitro dissolution studies}

Simvastatin content of the tablets was estimated by UVVisible spectrophotometric method based on the measurement of absorbance at $238 \mathrm{~nm}$ in phosphate buffer of $\mathrm{pH}$ 7.4. The method obeyed Beer's law in the concentration range $0-10 \mu \mathrm{g} / \mathrm{ml}$. No interference from the excipients used was observed. Drug release from matrix tablets was studied using 8 station dissolution rate test apparatus (Lab India, Disso 2000) employing a paddle stirrer at $40 \mathrm{RPM}$ and at $37 \pm 1^{\circ} \mathrm{C}$. Phosphate buffer of pH 7.4 (900 ml) was used as dissolution fluid. Samples of $5 \mathrm{ml}$ of each were withdrawn at different time intervals over a period of $12 \mathrm{~h}$. Each sample withdrawn was replaced with an equal amount of fresh dissolution medium. Samples were suitably diluted and assayed at $238 \mathrm{~nm}$ for Simvastatin using a Shimadzu
UV-140 double beam UV-spectrophotometer. The drug release experiments were conducted in triplicate. Results of in-vitro dissolution studies obtained were tabulated and shown graphically according to following models of data treatment ${ }^{5}$.

1. Cumulative Percentage Drug Release V/s Time in Hours.

2. Cumulative Percentage Drug Retained V/s Time in Hours.

3. Higuchi's Classical Diffusion Equation - Cumulative Percentage Drug Release V/s Square Root T.

4. Korsymeyer Peppas Equation - log cumulative \% Drug release V/s log Time

\section{RESULTS AND DISCUSSION}

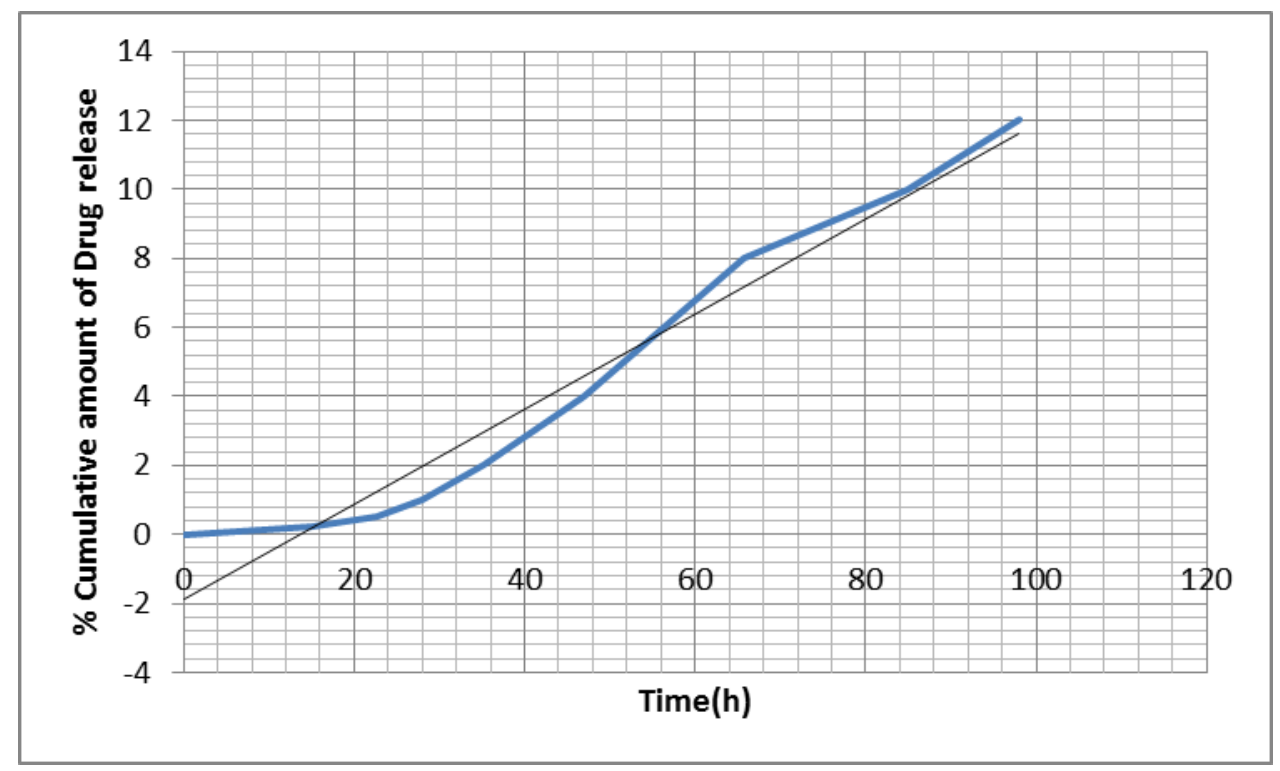

Figure 1: \% Cumulative drug release graph for suitable formulation

Deacetylated Xanthan Gum was prepared by gelatinizing Xanthan Gum in the presence of sodium hydroxide. The Deacetylated Xanthan Gum polymer formed was found to be dry and free flowing powder. It (C) 2011-15, JDDT. All Rights Reserved was insoluble in water, aqueous fluids of acidic and alkaline $\mathrm{pH}$. When tested for melting point, the polymer charred at $2200 \mathrm{C}$. Matrix tablets each containing $40 \mathrm{mg}$ of Simvastatin could be prepared employing different 
proportions of Deacetylated Xanthan Gum polymer by wet granulation technique. Hardness of the tablets was found to be in the range of $6-8 \mathrm{~kg} / \mathrm{sq}$. $\mathrm{cm}$. Weight loss in the friability test was less than $1 \%$ in all the batches. All the tablets contained Simvastatin within $100 \pm 5 \%$ of the labeled amount. Tablets have not disintegrated in water and aqueous, acidic $(\mathrm{pH}$ 1.2) and alkaline $(\mathrm{pH}$ 7.4) fluids. As such, the prepared tablets were of good quality with regard to drug content, hardness and friability. As the tablets formulated employing Deacetylated Xanthan Gum were non-disintegrating in acidic and alkaline fluids, they are considered suitable for oral controlled release. Release parameters of the tablets are summarized in Table 2. Simvastatin release from the prepared tablets was slow and spread over 12 h. and depended on the concentration of Deacetylated Xanthan Gum polymer. When the release data were analyzed as per zero and first order kinetic models, the best fit with higher correlation $\left(\mathrm{r}^{2}>0.9581\right)$ was observed with zero order models indicating that the drug release from all the tablets followed zero order kinetics. When the release data were analyzed for Peppas equation, the release exponent ' $n$ ' was found in the range $0.497-0.886$ indicating non - Fickian (anomalous) diffusion as the release mechanism from all the tablets prepared. Plots of percent released versus square root of time was found to be linear ( $r>0.948$ ) with most of the batches of tablets prepared indicating that the drug release from the tablets was diffusion controlled. As the polymer concentration was increased, release rate was decreased. The Good linear relationship was observed between percent polymer and release rate. Thus the drug release from the matrix tablets could be controlled by varying the proportion of drug: polymer in the matrix. Hence, matrix tablets formulated employing Deacetylated Xanthan Gum (F1) is considered suitable for controlling release of Simvastatin over $12 \mathrm{~h}$.

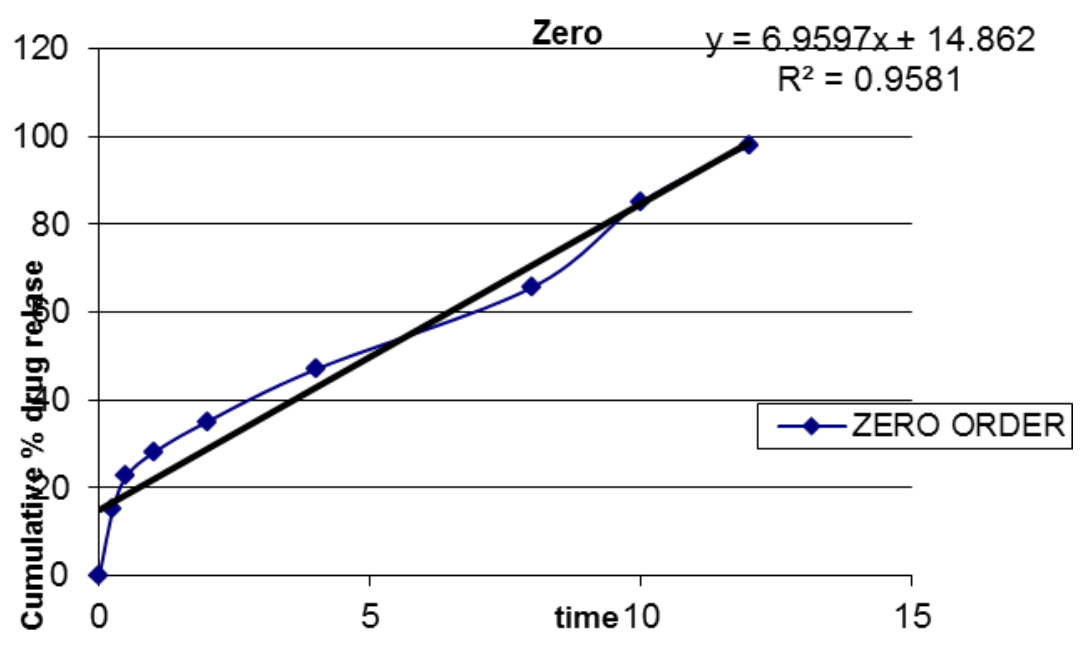

Figure 2: Zero Order release graph for suitable formulation

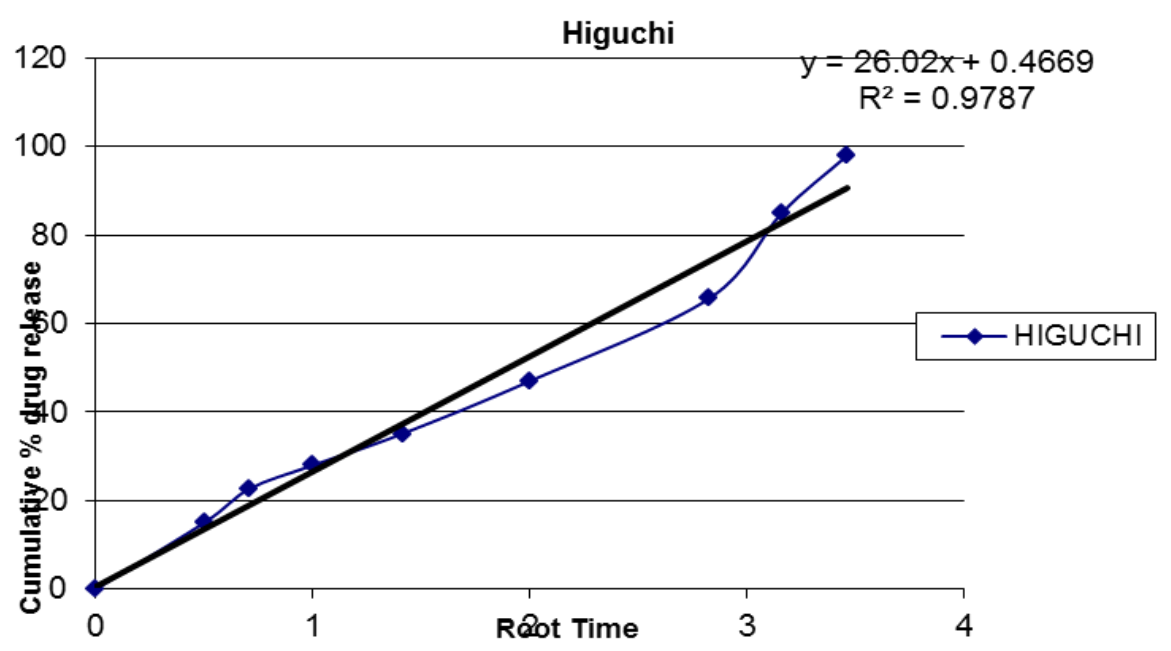

Figure 4: Higuchi's release profile for suitable formulation 


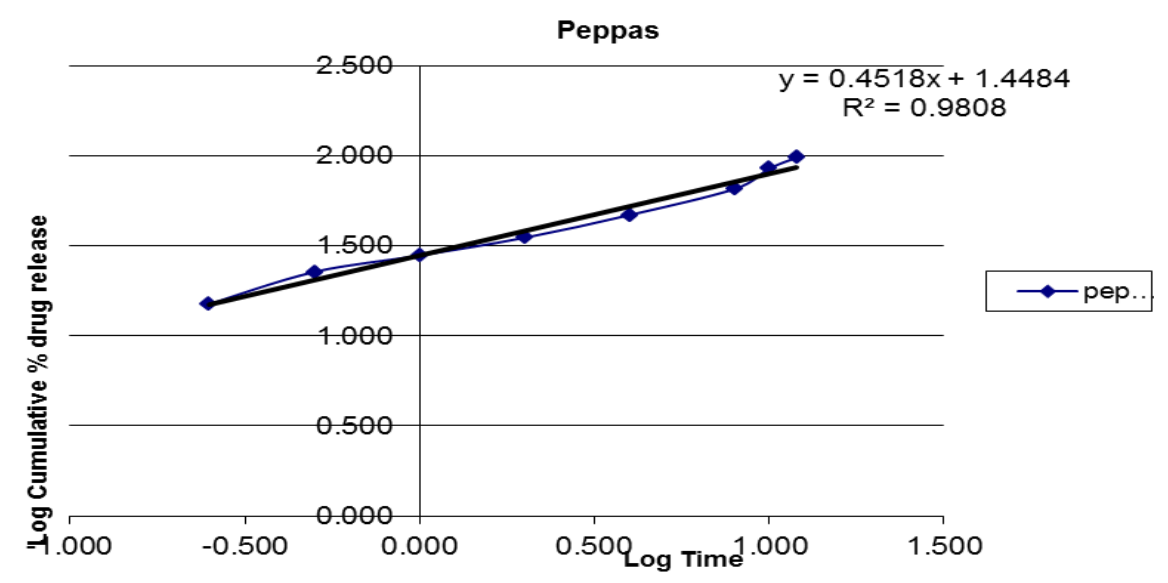

Figure 5: Korsymeyer Peppas release profile for suitable formulation

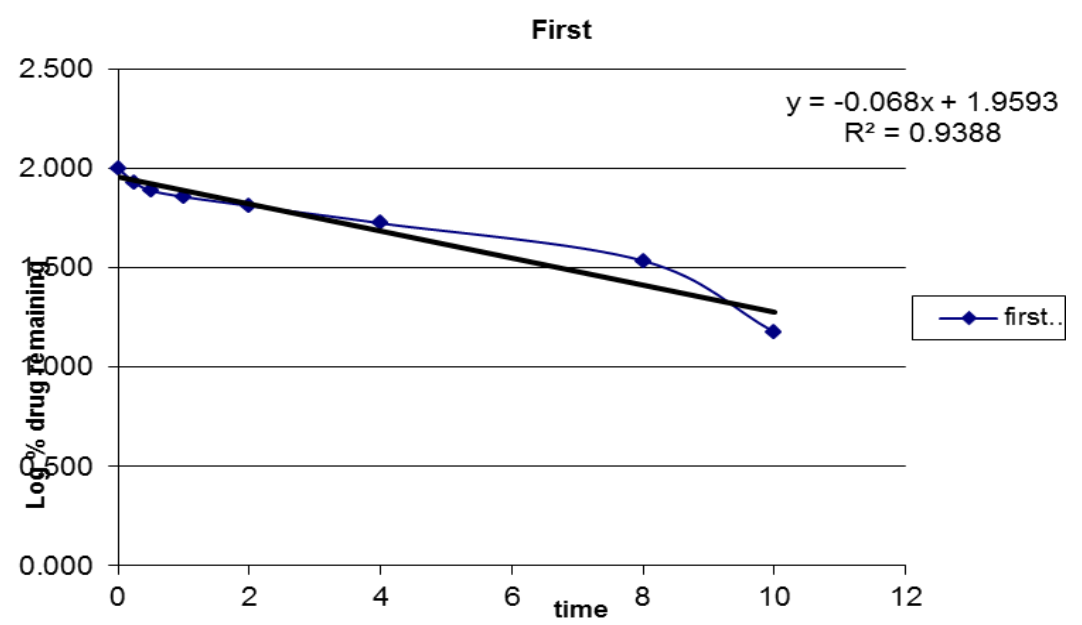

Figure 6: First order release profile for suitable formulation

\section{CONCLUSIONS}

Matrix tablets formulated employing Deacetylated Xanthan Gum, a new Xanthan Gum based polymer, are suitable for oral controlled release of Simvastatin. Drug release from the tablets formulated employing Deacetylated Xanthan Gum was slow and spread over $12 \mathrm{~h}$. and depended on percent polymer in the tablet. Release was diffusion controlled and followed zero order kinetics. Non - Fickian diffusion was the drug release mechanism from the formulated tablets. Simvastatin release from matrix tablets F1 formulated employing $37 \%$ Deacetylated Xanthan Gum polymer is Suitable controlled release formulation. Deacetylated

\section{REFERENCES}

1. Kottke MK, Chuech HR, Rhodes CT. Comparison of Disintegrant and binder activity of three corn starch products Drug Dev.Ind.Pharm. 1992, 18, 2207-2223.

2. Su L, Ji WK, Lan WZ, Dong XQ, Chemical modification of xanthan gum to increase dissolution rate Carbohydrate Polymers, 2003, 53(4), 497-499.

3. Herman J, Remon JP, Modified starches as hydrophilic matrices for controlled oral delivery, International Journal of Pharmaceutics. 1990, 63 (3), 201-205.

4. Kobayashi KA, Bauer LA, Horn JR, Opheim K, Wood F $\mathrm{Jr}$, Kradjan WA, Glipizide pharmacokinetics in young and elderly volunteers, Clin Pharm 1988, 7 (3), 224-228.
Xanthan Gum polymer is suitable for the design of oral controlled release tablets.

\section{ACKNOWLEDGEMENT}

We are thankful to the Management and Principal Vaageswari Institute of Pharmaceutical Sciences for their kind support and providing the necessary facilities to carry out this research work.

\section{CONFLICT OF INTEREST}

We are Glad to disclose we have No Conflict of interest.

5. Rang, M. M. Dale and J. M. Ritter. Pharmacology, 4th ed.London: Churchill Living Stone, 1999, P.230.

6. Higuchi T. Mechanism of sustained action medication theoretical analysis of rate of release of solid drugs dispersed in solid matrices. J Pharm Sci. 1963, 52, 1145-1149.

7. Ritger PL, Peppas NA. A simple equation for description of solute release II Fickian and anomalous release from swellable devices. J. Contr. Release, 1987, 5(1), 37-42. 